\title{
1 Phosphite ligands in Ru-based olefin metathesis 2 catalysts
}

3 Xavier Bantreil* • Catherine S. J. Cazin*

4

5 Received: ......./Accepted ...

6

7

8 Abstract In this short review, we focus on the synthesis and applications of

9 new phosphite-bearing ruthenium complexes in olefin metathesis. These

10 complexes were designed to take advantage of a known synergistic effect

11 between strong $\sigma$-donating NHC ligands and $\pi$-acidic phosphites. The

12 resulting catalysts display higher stability compared to their phosphine-

13 containing congeners. A comparative summary of their use in ring-closing

14 metathesis, cross metathesis and ring-opening metathesis polymerization is

15 presented as well as DFT calculations describing our mechanistic 16 understanding.

17

18 Keywords Phosphite $\bullet$ Metal Complexes • Metathesis • Coordination 19 Chemistry

22 C. S. J. Cazin $(\square)$

23 EaStCHEM School of Chemistry, University of St Andrews, St Andrews, 24 KY16 9ST, UK

25 e-mail: $\underline{\text { cc111@ st-andrews.ac.uk }}$ 
2 X. Bantreil

3 Institut des Biomolécules Max Mousseron (IBMM) UMR 5247 CNRS-

4 Université Montpellier-ENSCM Bâtiment Chimie (17), Faculté des

5 Sciences, Place Eugène Bataillon, 34095 Montpellier cedex 5, France

6

7

8 Introduction

9 Olefin metathesis represents one of the most important tools in

10 organometallic chemistry and catalysis [1-7]. Its relevance is highlighted

11 by its increasing importance at the industrial level. In addition, the award of

12 the Nobel Prize in 2005 to Y. Chauvin, R. H. Grubbs and R. R. Schrock for

13 their respective involvement in the discovery of olefin metathesis,

14 showcases its significance [8-10]. Since their pioneering work on

15 molybdenum (Schrock) and ruthenium (Grubbs) catalysts, numerous

16 studies have been performed to enhance the activity and lifetime of the

17 catalysts. Despite the importance of the molybdenum chemistry [11, 12],

18 this review will focus on the development of ruthenium complexes as they

19 have shown to be more user-friendly, thus far.

20 Since the discovery of a ruthenium vinylcarbene complex able to

21 catalyze the olefin metathesis reaction in 1992 [13], several developments

22 have led to ever more efficient catalysts. In particular, the introduction of a

23 benzylidene moiety led to the well-known Grubbs first-generation catalyst 
1 [14]. Next significant breakthroughs were the introduction of the 2-

2 isopropoxybenzylidene $[15,16]$ or 3-phenylinden-1-ylidene [17-20]

3 moieties in place of the benzylidene to furnish even more stable catalysts

4 (Figure 1).

5

6

< Fig. $1>$

7

8 Diversification of the catalyst structures was also performed by

9 replacement of one of the phosphane ligand with a $N$-heterocyclic carbene

10 (NHC). Since their discovery in 1991 by Arduengo [21], well-defined

11 NHCs have received significant attention as organocatalysts and ancillary

12 transition metal ligands. Indeed, these strongly $\sigma$-donating ligands

13 represent suitable replacements for tertiary phosphanes in numerous

14 organometallic complexes [22]. Diversification of their structure is

15 convenient and allows for the generation of families of tunable ligands in

16 terms of sterics and electronics. In ruthenium-catalyzed olefin metathesis,

17 the introduction of NHCs has had a critical and direct impact on catalyst

18 stability and efficiency, giving rise to second-generation catalysts [23-25].

19 SIMes ( $N, N$ '-bis(2,4,6-trimethylphenyl)-4,5-dihydroimidazolin-2-ylidene)

20 and $\operatorname{SIPr}$ (N,N'-bis(2,6-diisopropylphenyl)-4,5-dihydroimidazolin-2- 
1 ylidene) represent two of the most used NHC ligands for metathesis (Fig.

$22)$.

3

4

$<$ Fig. $2>$

5

6 Another possibility to enhance catalysts stability and activity was to

7 tune the so-called throwaway ligand. Numerous studies have been reported

8 on the substitution of the commonly used tricyclohexylphosphine by other

9 phosphanes [26-29], NHCs [30-33], pyridine [18, 34], and Schiff bases

10 [35-37] in the benzylidene and indenylidene families. The search for even

11 more stable and efficient catalysts led to studies based on the known

12 synergistic effect between strongly $\sigma$ donating NHCs and strongly $\pi$ acidic

13 phosphites on transition metals [38-41]. This short review will present and

14 discuss the synthesis of this new family of ruthenium NHC/phosphite

15 complexes, their catalytic efficiency and summarize mechanistic insights

16 into their stability and reactivity.

18 Synthesis of ruthenium NHC phosphites complexes

19 As stated above, the original thoughts behind these novel complexes were

20 to combine phosphites and NHC ligands around a ruthenium center to

21 obtain unreported structures. Consequently, several ruthenium complexes 
1 were synthesized, featuring various phosphites and NHCs in the

2 benzylidene and indenylidene series. In addition, the specific properties of

$3 \mathrm{NHC} /$ phosphite ruthenium complexes allowed for the generation of a

4 highly interesting cationic species via halogen abstraction.

Initial studies were performed using commercially available

6 indenylidene complex Ind-III, bearing SIMes and a pyridine ligand.

7 Simple substitution reactions involving Ind-III with different phosphites in

8 dichloromethane led to the displacement of the pyridine moiety (Table 1)

$9[42,43]$. Four phosphites featuring different sterics (Tolman cone angle

10 [44]) were evaluated, namely trimethyl, triethyl, triisopropyl and

11 triphenylphosphite, giving complexes cis-Caz-1a-d [45, 46]. Interestingly,

12 during the course of the reaction, two different complexes were observed

13 and assigned as the trans- and cis-dichloro isomers. In all cases, the trans

14 isomer was found to be the kinetic product of the reaction, which converted

15 upon heating and prolonged reaction times into the thermodynamic

16 product, the $\mathrm{cis}$ isomer. These structures still represent rare examples of

17 cis-dichloro ruthenium complexes for metathesis in which a monodentate

18 phosphorus ligand is involved [47, 48], and the first examples of

19 indenylidene-type complexes displaying such configuration. The cis-

20 dichloro geometry has been found more common in Hoveyda-type

21 complexes featuring bidentate ligands [49-58]. 
$4 \quad$ Formation of complexes cis-Caz-1a-d proceeded smoothly and

5 could be correlated to the phosphite steric hindrance. Indeed, phosphites

6 with a large cone angle such as $\mathrm{P}(\mathrm{OiPr})_{3}$ and $\mathrm{P}(\mathrm{OPh})_{3}$, required longer

7 reaction times than the smaller $\mathrm{P}(\mathrm{OMe})_{3}$ and $\mathrm{P}(\mathrm{OEt})_{3}$ (Table 1). Isolation

8 and study of the trans isomer was only possible when $\mathrm{P}(\mathrm{OiPr})_{3}$ was used.

9 Kinetic studies conducted using NMR spectroscopy of the trans/cis

10 isomerization for Caz-1a concluded that this process follows a

11 mononuclear and non-dissociative mechanism [42]. In addition, DFT

12 calculations demonstrated that for all $\mathrm{P}(\mathrm{OR})_{3}$-based systems, the cis

13 isomers were more stable than the trans relatives. This was found to

14 contrast with $\mathrm{PR}_{3}$-based complexes for which the trans isomer is favored

15 [59]. Thanks to this cis-dichloro configuration, cis-Caz-1a-d were also

16 shown to be significantly more thermally and bench stable than their

17 tricyclohexylphosphine analogs.

18 The introduction of a phosphite ligand in ruthenium-based

19 metathesis complexes led to a strong enhancement of stability due to a

20 phosphite/NHC synergism. Since then, attempts to introduce phosphites in

21 catalysts, which are known to decompose but also activate faster than Ind- 
1 II $\left[\mathrm{RuCl}_{2}(\mathrm{Ind})\left(\mathrm{PCy}_{3}\right)(\mathrm{SIMes})\right]$, have been carried out. Thus, focus was

2 placed on tuning of Ind-II' $\left[\mathrm{RuCl}_{2}(\mathrm{Ind})(\mathrm{PCy})(\mathrm{SIPr})\right]$ and G-II $3 \quad\left[\mathrm{RuCl}_{2}(=\mathrm{CHPh})\left(\mathrm{PCy}_{3}\right)(\mathrm{SIMes})\right]$ and replacement of the 4 tricyclohexylphosphine ligand. A similar synthetic strategy was applied to 5 obtain the corresponding complexes. The ruthenium pyridine adducts Ind6 III', $\left[\mathrm{RuCl}_{2}(\mathrm{Ind})(\mathrm{Py})(\mathrm{SIPr})\right]$, and G-III, $\left[\mathrm{RuCl}_{2}(=\mathrm{CHPh})(\mathrm{Py})_{2}(\mathrm{SIMes})\right]$ 7 were reacted with $\mathrm{P}(\mathrm{OEt})_{3}$ or $\mathrm{P}(\mathrm{OiPr})_{3}$ to yield respectively trans-Caz-2a-b 8 and trans-Caz-3a-b [60] (Scheme 1).

In contrast to previous results, the trans/cis isomerization could not

13 be easily achieved. Such isomerization could only be observed in the case

14 of Caz-2b, with concomitant decomposition. In the case of SIPr congeners,

15 this lack of isomerization was assigned to the increased steric bulk of the

16 SIPr ligand compared to SIMes, for which $\% V_{\text {bur }}$ are respectively 32.5 and

1730.0 [61-64]. This steric cause for reactivity was correlated with the fact

18 that the cis isomer was only observed with the complex bearing the

19 smallest phosphite $\mathrm{P}(\mathrm{OEt})_{3}$. Interestingly, X-ray data analysis showed that

20 in all cases, $\mathrm{Ru}-\mathrm{P}(\mathrm{OR})_{3}$ complexes presented $c a .0 .10 \AA$ shorter $\mathrm{Ru}-\mathrm{P}$ bond

21 than $\mathrm{Ru}-\mathrm{PCy}_{3}$ analogs. Even if phosphites are less $\sigma$-donating than 
1 phosphanes, their $\pi$-accepting character combined with strong $\sigma$-donor

2 NHC ligands resulted in stronger Ru-P bonds. This character could once

3 more be correlated to the increased stability of complexes Caz-2a-b when

4 compared to the parent compound $\left[\mathrm{RuCl}_{2}(\mathrm{Ind})(\mathrm{PCy})(\mathrm{SIPr})\right]$ Ind-II'. The excellent stability and catalytic activity of cis-Caz-1a prompted

6 the Cazin group to develop cationic derivatives of this compound [65].

7 Indeed, if neutral NHC ruthenium complexes are widely reported in the

8 literature, disclosures of syntheses describing related cationic systems

9 remain scarce [56, 66-69]. Reaction of cis-Caz-1a with 1 equivalent of 10 silver hexafluoroantimonate furnished cleanly $\mathbf{C a z}^{-1 a^{+}}$in $95 \%$ yield, in

11 which a chlorine atom was abstracted (Scheme 2) [65]. The resulting four-

12 coordinate 14-electron complex displays a sawhorse configuration with the

13 new vacant site being cis to the NHC and trans to the phosphite ligand.

17 When an additional equivalent of silver hexafluoroantimonate was added to 18 the reaction mixture to attempt a second chlorine abstraction, oxidation of $19 \mathrm{Ru}(\mathrm{II})$ to $\mathrm{Ru}(\mathrm{III})$ with concomitant reduction of $\operatorname{Ag}(\mathrm{I})$ to $\operatorname{Ag}(0)$ resulted in

20 the formation of $\mathbf{C a z}-\mathbf{1 a}^{2+}[65]$. This structure represents a rare example of

21 a $\mathrm{Ru}(\mathrm{III})$ four-coordinate bis-cationic complex. Interestingly, during the 
1 oxidation process, a cis/trans isomerization (related to $\mathrm{P}(\mathrm{OiPr})_{3}$ ) of the

2 chlorine atom was observed.

3 The crucial role of the phosphite was highlighted by 1) the extremely high

4 thermal stability of $\mathbf{C a z}-\mathbf{1 a}^{+}, 2$ ) the fact that chlorine abstraction from

5 phosphine or pyridine-containing analog complexes gave complex

6 mixtures of compounds.

7 Ten new ruthenium compounds bearing a NHC and a phosphite were thus

8 been readily synthesized and characterized. The beneficial effect of the

9 phosphite, when compared to parent phosphane, on the stability of the

10 complexes was unambiguously demonstrated. This improved stability was

11 shown to be an advantage in solution since the catalysts exhibited excellent

12 activity and prolonged lifetimes.

13

14 Catalytic activity of ruthenium NHC phosphite complexes

15 In order to understand the differences between the phosphite-containing 16 catalysts, reported data on ring-closing metathesis (RCM) have been

17 gathered in Table 2. Among the large range of examples studied for the 18 scope and application of these compounds, focus was placed on 19 compounds $\mathbf{6}$ and $\mathbf{8}$, known to be easy and difficult substrates in RCM, 20 respectively. In all cases, enhanced stability discussed in the previous 21 section directly translated in terms of catalytic activity when compared to 
1 phosphane analogs and allowed to conduct the catalytic reactions at very

2 low catalyst loadings. Among these, the general order of activity observed

3 with phosphane congeners is respected, that is Caz-1a,d and $\mathbf{C a z}-\mathbf{1}^{+}$were

4 efficient for difficult transformation and Caz-2a,b and Caz-3a,b for easy

5 substrates since they decompose faster at elevated temperatures.

6

7

8

9

10 were shown to have a latent character [43]. Indeed, when RCM of 8 in

11 toluene at $80^{\circ} \mathrm{C}$ catalyzed by trans-Caz-1a and cis-Caz-1a were monitored

12 by NMR spectroscopy, cis-Caz-1a clearly showed an activation period of 13 approximately $30 \mathrm{~min}$ [42]. The same behavior was witnessed with the

14 other $\left[\mathrm{RuCl}_{2}(\mathrm{Ind})\left\{\mathrm{P}(\mathrm{OR})_{3}\right\}\right.$ (SIMes) $]$ catalysts. As shown in Tables 1 and 2,

15 catalytic activity in this series is directly linked to phosphite bulk.

16 Complexes bearing bulky phosphites, namely $\mathrm{P}(\mathrm{OiPr})_{3}$ and $\mathrm{P}(\mathrm{OPh})_{3}$, were

17 found to activate faster than those bearing smaller phosphites, giving rise to

18 better conversions for easy and difficult substrates (Table 2, entries 1-4 and

19 12-15). As a comparison, the tricyclohexylphosphane analog Ind-II gave

20 only $61 \%$ conversion when the use of cis-Caz-1a permitted to reach

21 complete conversion of hindered substrate 8. Among this series of 
1 catalysts, cis-Caz-1a proved to be the most efficient and allowed to

2 perform RCM of various benchmark substrates with catalyst loadings as

3 low as $0.05 \mathrm{~mol} \%$ and $0.1 \mathrm{~mol} \%$ for easy and difficult substrates,

4 respectively $[42,43]$.

6 even more thermally stable than cis-Caz-1a [65]. In order to obtain high

7 conversions reactions required to be carried out at $140^{\circ} \mathrm{C}$ in xylene. After

815 min with only 0.1 and $0.2 \mathrm{~mol} \%$ of $\mathbf{C a z}^{+} \mathbf{1}^{+}$, cyclized products 7 and 9

9 were obtained with $99 \%$ and $90 \%$ conversion, respectively (Table 2, entries

105 and 17). It is important to note that at $140^{\circ} \mathrm{C}$, even cis-Caz-1a

11 decomposed rapidly while $\mathbf{C a z}-\mathbf{1}^{+}$still proved active. Such stability and

12 catalytic activity (down to $0.1 \mathrm{~mol} \%$ ) has never been reported for cationic

13 ruthenium complexes in olefin metathesis.

14 Catalysts Caz-2a,b and Caz-3a,b are derived from complexes Ind-

15 II' and G-II which activate rapidly but also decompose at rather low 16 temperatures $\left(50^{\circ} \mathrm{C}\right)$. However, as stability was enhanced by the

17 introduction of phosphites, $\mathrm{RCM}$ reactions had to be conducted at $50^{\circ} \mathrm{C}$ to 18 ensure good catalyst activation [59]. If the fastest initiation of Ind-II' was 19 shown evident by the results on unhindered substrate 6 (Table 2, entries 620 8), the superiority of $\mathbf{C a z - 2 a , b}$ was obvious when hindered compound 10 21 was cyclized (Table 2, entries 21-23). Caz-3a,b were also found to be 
1 slightly more active than G-II on RCM of $\mathbf{6}$ (Table 2, entry 9-11) but their

2 higher stability could be used as an advantage with substrate 8 [60]. After

$38 \mathrm{~h}$ in $\mathrm{MTBE}$ at $50^{\circ} \mathrm{C}$, tetra-substituted cyclized product 9 was obtained

4 with $25 \%, 63 \%$ and $42 \%$ conversion in the presence of 2 mol\% of G-II,

5 Caz-3a and Caz-3b, respectively (Table 2, entries 18-20). As for G-II,

6 heating reactions at higher temperature did not allow for better results and

7 led to decomposition of complexes Caz-3a,b.

The best catalysts of each series were also evaluated in enyne RCM

9 (EYRCM) and cross metathesis (CM) at low catalyst loading (Tables 3 and

10 4). In EYRCM, latent catalysts Caz-1a and $\mathbf{C a z}-1 \mathbf{a}^{+}$were not as efficient

11 as for RCM [43, 65]. Indeed, RCM of enynes $\mathbf{1 2}$ and $\mathbf{1 4}$ into dienes $\mathbf{1 3}$ and

$12 \mathbf{1 5}$, respectively, did not produce more than an $80 \%$ yield (Table 3 , entries

13 1-3). Such yields, even though not optimal, were obtained with as low as

$140.075 \mathrm{~mol} \%$ of catalyst. On the contrary, Caz-2b, featuring SIPr and $15 \mathrm{P}(\mathrm{OEt})_{3}$ ligands, gave excellent results and allowed to isolate 15 in $94 \%$ 16 yield with only 0.1 mol\% of catalyst (Table 3, entry 4) [59]. Finally, even if

17 working at lower temperature, Caz-3a gave similar results as Caz-1a and 18 Caz-1 $^{+}$. However, Caz-3a was demonstrated to be more efficient than G-II 19 on difficult EYRCM substrates [60]. 
To study CM, substrates $\mathbf{1 6}$ and $\mathbf{1 8}$ were reacted with 5 equivalents

3 of methyl acrylate. All phosphite-containing catalysts were able to promote

4 this reaction efficiently (Table 4). Indeed, alkene $\mathbf{1 6}$ was readily converted

5 with yields of up to $79 \%$ when 0.2 mol\% of Caz-1 ${ }^{+}$were used (Table 4,

6 entry 2) [65]. Interestingly, Caz-3a was found as efficient as G-II for this

7 transformation [60]. Compound $\mathbf{1 7}$ was obtained in $72 \%$ yield (Table 4,

8 entries 3 and 4). Caz-1a permitted the use of even lower catalyst loading

9 since only 0.075 mol\% catalyst afforded $68 \%$ isolated yield of the desired

10 product (Table 4, entry 1) [43]. Finally, compound 19 could be isolated in

11 good yield when using Caz-1a and Caz-2b at 0.2 mol\% (Table 4, entries 5

12 and 6) [42, 43, 59].

13

16 Since cis-Caz-1a possesses this particular reactivity, it was screened

17 in recent studies and compared to other commercially available catalysts.

18 Lamaty and co-workers showed that cis-Caz-1a was able to promote RCM

19 of dienes $\mathbf{2 0}$ and $\mathbf{2 2}$ under microwave activation in polyethylene glycol

20 (PEG) as green solvent for metathesis [70]. However, it was necessary to

21 use methylated PEG (MeO-PEG-2000-OMe) in order to avoid the 
1 formation of a Ru-hydride species, which promoted isomerization of

2 olefins, and thus formation of undesired side-products (Scheme 3).

3

4

5

6

7 fragrances, namely $\delta$-decalactone and exaltolide, and compared it to a

8 series of standard and fast initiation commercially available precatalysts

9 [71]. Even though cis-Caz-1a is latent and thus initiates slowly, it was

10 shown highly active in the RCM of diene $\mathbf{2 4}$ and led to the highest yield of

$1169 \%$ in the macrolactonization/hydrogenation of 25 (Scheme 4). The

12 authors highlighted the fact that the latter result was, in terms of catalyst

13 efficiency and concentration, a significant improvement over the state-of-

14 the-art [72-74].

15 Latent and highly stable catalysts are interesting in ring-opening 16 metathesis polymerization (ROMP) since they allow control of 17 polymerization by controlling the initiation trigger (e.g. heat, light, 18 mechanical force). Thus, phosphite-containing complexes cis-Caz-1a and

19 Caz-2a were evaluated in the ROMP of model substrate endo,exo-

20 bicyclo[2.2.1]hept-5-ene-2,3-dicarboxylic acid dimethyl ester (Mon-1) and

21 endo,exo-bicyclo[2.2.1] hept-5-ene-2,3-diphenyl ketone (Mon-2) [59]. At 
1 room temperature, cis-Caz-1a gave less than $10 \%$ conversion after $24 \mathrm{~h}$ of

2 reaction and Caz-2a revealed to be a slower initiator than phosphane

3 analog Ind-II' (Table 5, entries 1,2 and 4). Caz-2a gave a polymer

4 characterized by a number-average molecular weight $\left(M_{\mathrm{n}}\right)$ value of 131000

$5 \mathrm{~g} / \mathrm{mol}$ and a polydiversity index (PDI) of 1.6. As a comparison, Ind-II and

6 Ind-III featuring a SIMes ligand were much better initiators (Table 5,

7 entries 3 and 5). At higher temperature, cis-Caz-1a was able to initiate

8 polymerization to furnish a polymer with $M_{\mathrm{n}}$ value of $106000 \mathrm{~g} / \mathrm{mol}$ and a

9 PDI of 1.8 (Table 5, entry 6). Even at $80^{\circ} \mathrm{C}$, cis-Caz-1a proved less active 10 than Caz-2a.

11 Kinetic study of the polymerization of Mon-2 at $25^{\circ} \mathrm{C}$ confirmed

12 that i) cis-Caz-1a to be less active than Caz-2a, ii) Caz-2a was less active

13 than the phosphane parent compound Ind-II'. Such information is in

14 agreement with the fact that phosphites have a higher re-coordination 15 ability than phosphanes during catalysis, thus explaining the higher 16 stability but also lower activity of $\mathrm{P}(\mathrm{OR})_{3}$-containing initiators.

20 In a parallel study, Ind-II and cis-Caz-1a were evaluated in the

21 ROMP of dicyclopentadiene (DCPD), an inexpensive by-product of C5 
1 stream of naphtha crackers [75]. The corresponding polymer pDCPD is

2 highly valuable and its use is becoming more prevalent in view of its

3 outstanding properties, i.e. chemical resistance, high rigidity and

4 robustness. The synthetic approach to pDCPD involving ROMP is

5 generally performed using Grubbs first or second-generation catalysts. The

6 use of an air and moisture stable initiator such as cis-Caz-1a would provide

7 a competitive approach to this polymer. It has been established that $20 \mathrm{ppm}$

8 of Ind-II or $25 \mathrm{ppm}$ of $\mathrm{cis}$-Caz-1a were sufficient to furnish pDCPD with

9 similar mechanical properties to industrially made $\mathrm{pDCPD}$, i.e. Young's

10 modulus (E) of $1.78 \pm 0.1$, and a maximal stress $R_{\mathrm{m}}$ value of $50 \pm 3 \mathrm{MPa}$

11 (values for pDCPD obtained with cis-Caz-1a). In addition, involvement of

12 Ind-II and thermally latent initiator cis-Caz-1a instead of G-II widened

13 the processing window of the DCPD/initiator formulation, at room

14 temperature, to minutes and several hours before curing, respectively.

16 Mechanistic investigation

17 Among the phosphite-containing catalysts described above, the peculiar 18 cis-dichloro arrangement in Caz-1a-d raised numerous mechanistic 19 questions. In particular, investigations addressing the higher stability of

20 these complexes over phosphane analogs and on the catalytic mechanism

21 have been carried out. 
1 DFT calculations of the relative energy of the cis and trans isomer

2 showed that the cis isomer was more stable [43]. Moreover, this relative

3 energy is in linear correlation with Tolman cone angle of the phosphite

4 ligands. Similar calculations on phosphane-containing complexes

5 confirmed that, in this case, the trans isomer was the most stable.

6 Calculations of absolute bond dissociation energies (DBE) were performed

7 on $\mathrm{P}(\mathrm{OMe})_{3}$ and $\mathrm{PMe}_{3}$ as model ligands to minimize steric influence. In the

8 trans isomers, values obtained for the phosphite $(14.6 \mathrm{kcal} / \mathrm{mol})$ were

9 smaller than for the phosphane $(22.3 \mathrm{kcal} / \mathrm{mol})$, showing that the less

10 donating $\mathrm{P}(\mathrm{OMe})_{3}$ should dissociate more rapidly than $\mathrm{PMe}_{3}$. However, in

11 the cis isomer, the $\mathrm{BDE}$ values for $\mathrm{P}(\mathrm{OMe})_{3}(21.8 \mathrm{kcal} / \mathrm{mol})$ were higher

12 than for $\mathrm{PMe}_{3}(20.5 \mathrm{kcal} / \mathrm{mol})$, indicating a stronger binding of the

13 phosphite. In addition, structural analysis showed that the average P-O

14 bond in the cis isomer was $0.01 \AA$ longer than in the trans isomer. This

15 difference is a clear indication of back-donation from the metal into the $\pi^{*}$

16 orbitals corresponding to P-O bonds [76], and explains the difference in

17 binding strength between phosphites and phosphanes.

18 Such data provided some insight into the activation mechanism of

19 cis-Caz-1a-d. Indeed, BDE calculations suggest that dissociation of the

20 phosphite, if it occurs, would be favored when $\mathrm{P}(\mathrm{OR})_{3}$ is trans to the NHC.

21 In addition, when bulkier olefins than ethylene are involved in the 
1 metathesis, the possibility of an activation step through an associative-

2 displacement mechanism as suggested for Hoveyda-Grubbs catalysts was

3 ruled out [77]. The energies associated with complexes in which

4 coordination of ethylene prior to dissociation of a phosphite ligand was

5 involved were found too high to be reasonable.

All these data seem to indicate that the cis isomer of Caz-1a-d plays

7 the role of a reservoir for the trans isomer. Thus, when cis-Caz-1a-d pre-

8 catalysts are used in catalysis in toluene, throughout the reaction, the cis

9 isomer releases progressively trans-Caz-1a-d. Then the trans isomer can

10 follow the classical metathesis mechanism, i.e. first initiation by release of

11 the throwaway ligand, in this case, the phosphite, and metathesis with the

12 substrate that generates the 14-electron active species that can enter the

13 catalytic cycle to afford the desired metathesis product (Scheme 5).

\section{Conclusion}

18 In summary, the synthesis of new ruthenium complexes featuring a NHC 19 and a phosphite ligand has been reviewed. The expected synergism

20 between $\sigma$-donating $\mathrm{NHC}$ and $\pi$-acidic phosphite was unambiguously

21 demonstrated in olefin metathesis as all novel complexes showed an 
1 enhanced stability when compared to $\mathrm{PCy}_{3}$-containing congeners. In

2 particular, the original cis-dichloro configuration in the Caz-1a-d series

3 gave rise to latent and highly stable catalysts. The phosphite catalysts

4 showed excellent activities in RCM, EYRCM and CM and their superiority

5 over phosphane analogs became apparent as soon as "difficult" substrates

6 were tested, especially at low catalyst loading. In addition, Caz-2a,

7 featuring $\mathrm{SIPr}$ and $\mathrm{P}(\mathrm{OiPr})_{3}$ ligands, and cis-Caz-1a, featuring SIMes and

$8 \mathrm{P}(\mathrm{OiPr})_{3}$ ligands, showed interesting activities in ROMP. In the case of

9 Caz-1a-d, calculations and kinetic experiments demonstrated that cis/trans

10 isomerization proceeded through a mononuclear non-dissociative

11 mechanism. During catalysis, such isomerization might occur prior to the

12 initiation and propagation steps.

13

\section{Acknowledgements}

15 The authors gratefully acknowledge the Royal Society (University

16 Research Fellowship to CSJC), the CNRS (Centre National de la

17 Recherche Scientifique) and l'Université de Montpellier for funding.

\section{References}


1 1. Grubbs RH, Wenzel AG and Chatterjee AK (2007) In Olefin cross-

2 metathesis, Elsevier Ltd., p 179.

3 2. Kotha S and Lahiri K (2007) Synlett 2767.

4 3. Hoveyda AH and Zhugralin AR (2007) Nature 450:243.

5 4. Deshmukh PH and Blechert S (2007) Dalton Trans 2479.

6 5. Compain P (2007) Adv Synth Catal 349:1829.

7 6. Astruc D (2005) New J Chem 29:42.

8 7. Deiters A and Martin SF (2004) Chem Rev 104:2199.

9 8. Schrock RR (2007) Adv Synth Catal 349:41.

10 9. Grubbs RH (2007) Adv Synth Catal 349:34.

11 10. Chauvin Y (2007) Adv Synth Catal 349:27.

12 11. Hoveyda AH (2014) J Org Chem 79:4763.

13 12. Deraedt C, d'Halluin M and Astruc D (2013) Eur J Inorg Chem $14 \quad 2013: 4881$.

15 13. Nguyen ST, Johnson LK, Grubbs RH and Ziller JW (1992) J Am 16 Chem Soc 114:3974.

17 14. Schwab P, France MB, Ziller JW and Grubbs RH (1995) Angew 18 Chem Int Ed 34:2039.

19 15. Kingsbury JS, Harrity JPA, Bonitatebus PJ and Hoveyda AH (1999) 20 J Am Chem Soc 121:791. 
1 16. Garber SB, Kingsbury JS, Gray BL and Hoveyda AH (2000) J Am

2 Chem Soc 122:8168.

3 17. Boeda F, Clavier H and Nolan SP (2008) Chem Commun 2726.

4 18. Clavier H, Petersen JL and Nolan SP (2006) J Organomet Chem $5 \quad 691: 5444$.

6 19. Dragutan V, Dragutan I and Verpoort F (2005) Platinum Met Rev $7 \quad 49: 33$.

8 20. Urbina-Blanco CA, Guidone S, Nolan SP and Cazin CSJ (2014) In

9 Ruthenium-indenylidene and other alkylidene containing olefin metathesis

10 catalysts, John Wiley \& Sons, Inc., p 417.

11 21. Arduengo AJ, III, Harlow RL and Kline M (1991) J Am Chem Soc $12 \quad 113: 361$.

13 22. Bantreil X, Broggi J and Nolan SP (2009) Annu Rep Prog Chem, 14 Sect B: Org Chem 105:232.

15 23. Díez-González S, Marion N and Nolan SP (2009) Chem Rev $16 \quad 109: 3612$.

17 24. Colacino E, Martinez J and Lamaty F (2007) Coord Chem Rev $18 \quad 251: 726$.

19 25. Vougioukalakis GC and Grubbs RH (2010) Chem Rev 110:1746.

20 26. Sanford MS, Ulman M and Grubbs RH (2001) J Am Chem Soc $21 \quad 123: 749$. 
1 27. Sanford MS, Love JA and Grubbs RH (2001) J Am Chem Soc $2 \quad 123: 6543$.

3 28. Broggi J, Urbina-Blanco CA, Clavier H, Leitgeb A, Slugove C, 4 Slawin AMZ and Nolan SP (2010) Chem Eur J 16:9215.

5 29. Urbina-Blanco CA, Manzini S, Gomes JP, Doppiu A and Nolan SP 6 (2011) Chem Commun 47:5022.

7 30. Vorfalt T, Leuthäußer S and Plenio H (2009) Angew Chem Int Ed $8 \quad 48: 5191$.

9 31. Sashuk V, Peeck LH and Plenio H (2010) Chem Eur J 16:3983.

10 32. Bantreil X, Randall RAM, Slawin AMZ and Nolan SP (2010)

11 Organometallics 29:3007.

12 33. Peeck LH and Plenio H (2010) Organometallics 29:2761.

13 34. Urbina-Blanco CA, Leitgeb A, Slugove C, Bantreil X, Clavier H, 14 Slawin AMZ and Nolan SP (2011) Chem Eur J 17:5045.

15 35. Opstal T and Verpoort F (2002) Synlett 2002:0935.

16 36. Opstal T and Verpoort F (2003) Angew Chem Int Ed 42:2876.

17 37. Vila AML, Monsaert S, Drozdzak R, Wolowiec S and Verpoort F 18 (2009) Adv Synth Catal 351:2689.

19 38. Diebolt O, Jurč́́k V, Correa da Costa R, Braunstein P, Cavallo L,

20 Nolan SP, Slawin AMZ and Cazin CSJ (2010) Organometallics 29:1443. 
1 39. Bedford RB, Hazelwood SL and Limmert ME (2002) Chem

2 Commun 22:2610.

3 40. Bedford RB, Cazin CSJ and Hazelwood SL (2002) Angew Chem Int $4 \quad \operatorname{Ed} 41: 4120$.

5 41. Ho C-Y and Jamison TF (2007) Angew Chem Int Ed 46:782.

6 42. Bantreil X, Schmid TE, Randall RAM, Slawin AMZ and Cazin CSJ 7 (2010) Chem Commun 46:7115.

8 43. Bantreil X, Poater A, Urbina-Blanco CA, Bidal YD, Falivene L,

9 Randall RAM, Cavallo L, Slawin AMZ and Cazin CSJ (2012)

10 Organometallics 31:7415.

11 44. Tolman CA (1977) Chem Rev 77:313.

12 45. Cazin C (2013) Ruthenium metathesis polymerization catalysts.

13 WO2013045876A1.

14 46. Cazin C (2011) Ruthenium complexes for use in olefin metathesis. 15 WO2011117571A1.

16 47. Nguyen ST, Grubbs RH and Ziller JW (1993) J Am Chem Soc $17 \quad 115: 9858$.

18 48. Prühs S, Lehmann CW and Fürstner A (2003) Organometallics $19 \quad 23: 280$.

20 49. Ung T, Hejl A, Grubbs RH and Schrodi Y (2004) Organometallics $21 \quad 23: 5399$. 
1 50. Barbasiewicz M, Bieniek M, Michrowska A, Szadkowska A, Makal

2 A, Woźniak K and Grela K (2007) Adv Synth Catal 349:193.

3 51. Ben-Asuly A, Tzur E, Diesendruck CE, Sigalov M, Goldberg I and 4 Lemcoff NG (2008) Organometallics 27:811.

5 52. Diesendruck CE, Tzur E, Ben-Asuly A, Goldberg I, Straub BF and 6 Lemcoff NG (2009) Inorg Chem 48:10819.

7 53. Poater A, Ragone F, Correa A, Szadkowska A, Barbasiewicz M, 8 Grela K and Cavallo L (2010) Chem Eur J 16:14354.

9 54. Tzur E, Ivry E, Diesendruck CE, Vidavsky Y, Goldberg I and 10 Lemcoff NG (2014) J Organomet Chem 769:24.

11 55. Leitgeb A, Mereiter K and Slugove C (2012) Monatsh Chem $12 \quad 143: 901$.

13 56. Zirngast M, Pump E, Leitgeb A, Albering JH and Slugove C (2011)

14 Chem Commun 47:2261.

15 57. Pump E, Fischer RC and Slugove C (2012) Organometallics $16 \quad 31: 6972$.

17 58. Aharoni A, Vidavsky Y, Diesendruck CE, Ben-Asuly A, Goldberg I 18 and Lemcoff NG (2011) Organometallics 30:1607.

19 59. Urbina-Blanco CA, Bantreil X, Wappel J, Schmid TE, Slawin AMZ,

20 Slugovc C and Cazin CSJ (2013) Organometallics 32:6240. 
1 60. Schmid TE, Bantreil X, Citadelle CA, Slawin AMZ and Cazin CSJ

2 (2011) Chem Commun 47:7060.

3 61. Leitgeb A, Abbas M, Fischer RC, Poater A, Cavallo L and Slugove 4 C (2012) Catal Sci Technol 2:1640.

5 62. Ragone F, Poater A and Cavallo L (2010) J Am Chem Soc 132:4249.

6 63. Poater A, Cosenza B, Correa A, Giudice S, Ragone F, Scarano V and 7 Cavallo L (2009) Eur J Inorg Chem 1759.

8 64. Clavier H, Correa A, Cavallo L, Escudero-Adan EC, Benet-

9 Buchholz J, Slawin AMZ and Nolan SP (2009) Eur J Inorg Chem 1767.

10 65. Songis O, Slawin AMZ and Cazin CSJ (2012) Chem Commun $11 \quad 48: 1266$.

12 66. Wang D, Wurst K, Knolle W, Decker U, Prager L, Naumov S and

13 Buchmeiser MR (2008) Angew Chem, Int Ed 47:3267.

14 67. Volland MAO, Hansen SM, Rominger F and Hofmann P (2004)

15 Organometallics 23:800.

16 68. Miyaki Y, Onishi T and Kurosawa H (2000) Inorg Chim Acta 300$17 \quad 302: 369$.

18 69. Fuerstner A, Liebl M, Lehmann CW, Picquet M, Kunz R, Bruneau

19 C, Touchard D and Dixneuf PH (2000) Chem - Eur J 6:1847.

20 70. Bantreil X, Sidi-Ykhlef M, Aringhieri L, Colacino E, Martinez J and 21 Lamaty F (2012) J Catal 294:113. 
1 71. Caijo F, Tripoteau F, Bellec A, Crevisy C, Basle O, Mauduit M and 2 Briel O (2013) Catal Sci Technol 3:429.

3 72. Louie J, Bielawski CW and Grubbs RH (2001) J Am Chem Soc $4 \quad 123: 11312$.

5 73. Fürstner A and Langemann K (1997) Synthesis 1997:792.

6 74. Hagiwara H, Nakamura T, Okunaka N, Hoshi T and Suzuki T (2010) 7 Helv Chim Acta 93:175.

8 75. Leitgeb A, Wappel J, Urbina-Blanco CA, Strasser S, Wappl C, Cazin 9 CSJ and Slugovc C (2014) Monatsh Chem 145:1513.

10 76. Orpen AG and Connelly NG (1985) J Chem Soc, Chem Commun 111310.

12 77. Thiel V, Hendann M, Wannowius K-J and Plenio H (2012) J Am 13 Chem Soc 134:1104.

14 


\section{$1 \quad$ Figure Captions}

2 Fig. 1 General structures of the families of ruthenium catalysts for olefin

3 metathesis<smiles>Cl[R](Cl)([Pb])/C=C/c1ccccc1</smiles>

$4 \quad$ Vinylcarbene

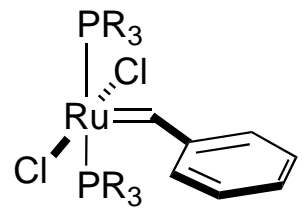

Benzylidene<smiles></smiles>

Boomerang-type

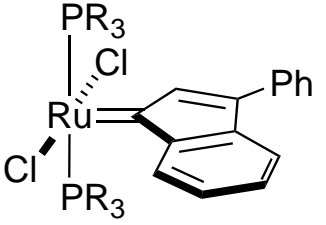

Indenylidene

5

6 Fig. 2 Structure of SIMes and SIPr and derived ruthenium olefin metathesis

7 catalysts
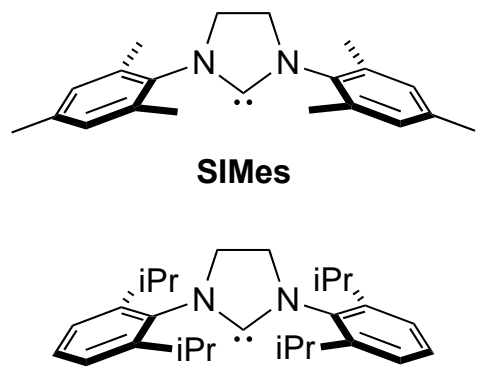

SIPr

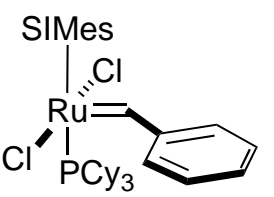

G-II

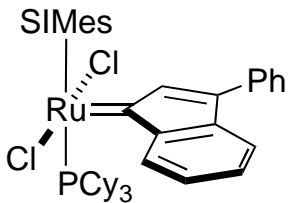

Ind-II

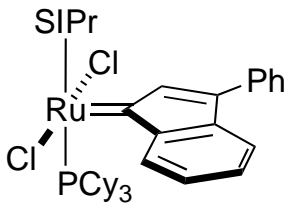

Ind-II' 
1

2 Schemes

\section{$3 \quad$ Scheme 1}

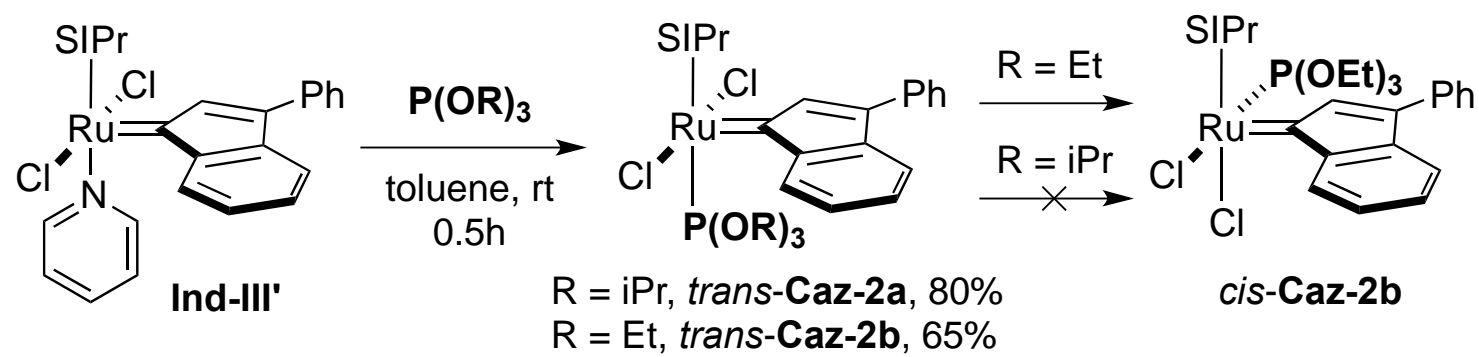<smiles></smiles>

4

\section{Scheme 2}

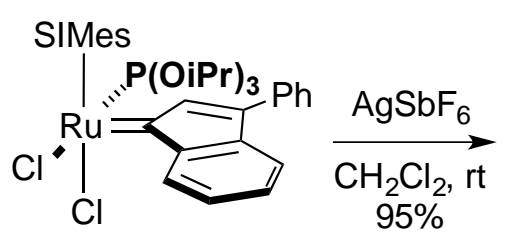

6

cis-Caz-1a
$\mathrm{R}=\mathrm{iPr}$, trans-Caz-3a, 78\%

$\mathrm{R}=\mathrm{Et}$, trans-Caz-3b, 70\%

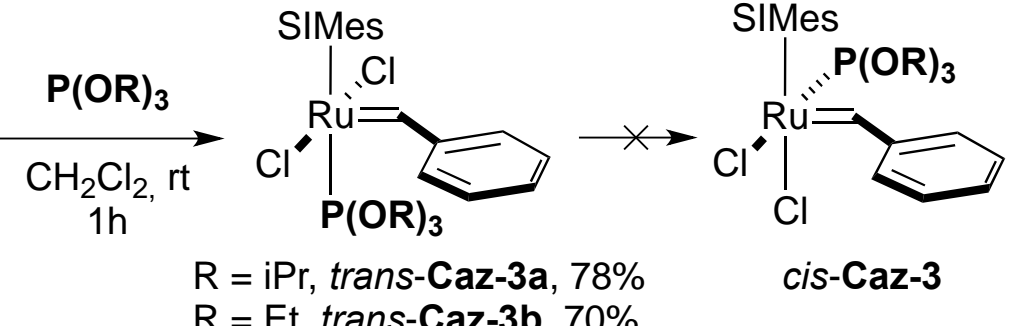

cis-Caz-3

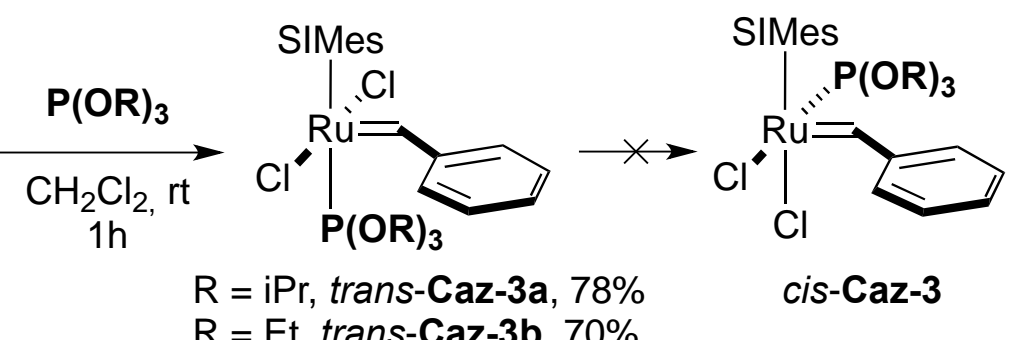

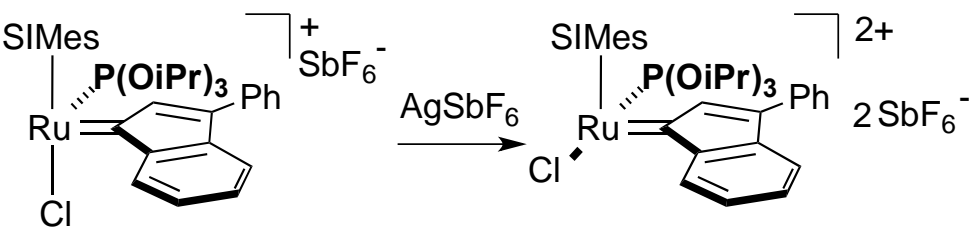

Caz-1a ${ }^{+}, 95 \%$

Caz-1a ${ }^{++}, 95 \%$

7

8 Scheme 3 
<smiles>C=CCC(C)(C)N([AsH])CC(=C)C</smiles>

$\mathrm{n}=1,20$

$\mathrm{n}=2,22$

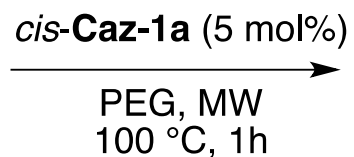

$100^{\circ} \mathrm{C}, 1 \mathrm{~h}$

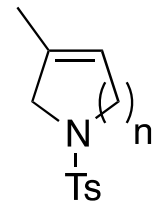

21

\section{PEG-3400}

$\mathrm{n}=1$,

$\mathrm{n}=2$,

MeO-PEG-2000-OMe

$93 \%$

$83 \%$

\section{Scheme 4}
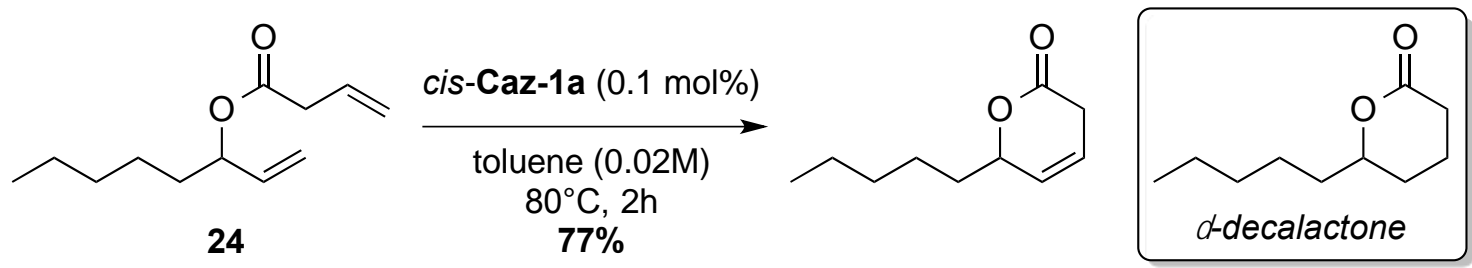<smiles>C=CCOC(=O)[AlH]/C=C\C</smiles>

25
1) cis-Caz-1a (1 mol\%) toluene $(0.01 \mathrm{M})$ $80^{\circ} \mathrm{C}, 4 \mathrm{~h}$

2) $\mathrm{Pd} / \mathrm{C}, \mathrm{H}_{2}$

$69 \%$

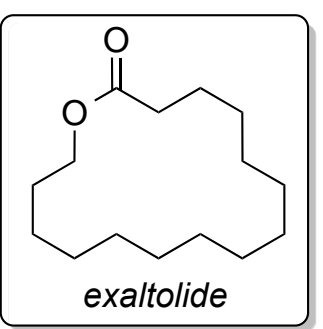

3

4

5 Scheme 5 


$$
\text { SIMes-Caz-1a-d }
$$
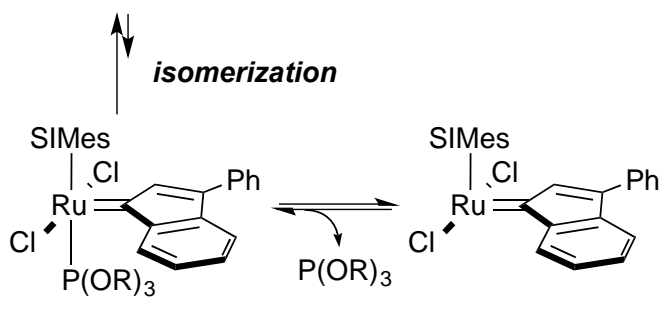
trans-Caz-1a-d

\section{Initiation}

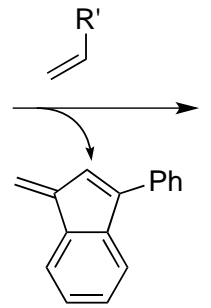

$\mathrm{H}_{2} \mathrm{C} \underset{-\mathrm{CH}_{2}}{ }$

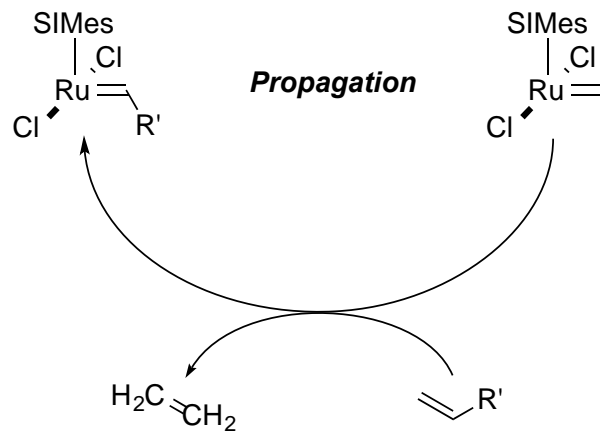


1 Table 1 Synthesis of complexes cis-Caz-1a-d

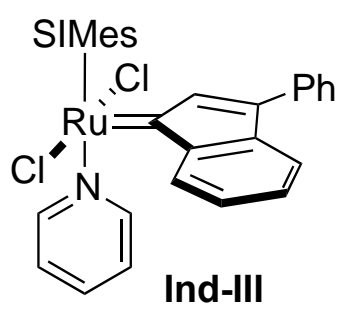

2

3 Entry $\mathrm{P}(\mathrm{OR})_{3}$ (equiv.)

$4 \quad 1$

$\mathrm{P}(\mathrm{OMe})_{3}(1)$

$\mathrm{P}(\mathrm{OEt})_{3}(1)$

$\mathrm{P}(\mathrm{OiPr})_{3}(1)$

$\mathrm{P}(\mathrm{OPh})_{3}(4)$

$130 \quad 15$

$5 \quad 2$

1095

$\begin{array}{ll}6 & 3\end{array}$

$128 \quad 15$

74

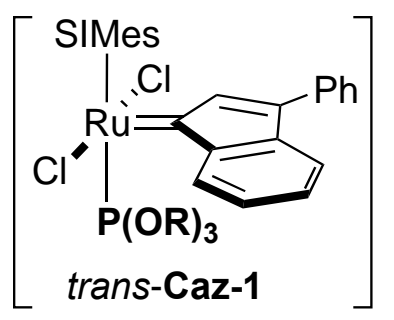

kinetic

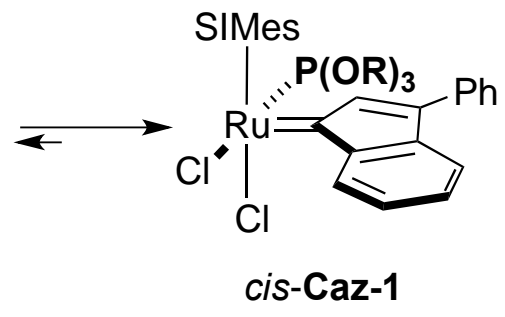

thermodynamic

88

cis-Caz-1c

84

cis-Caz-1a

${ }^{\mathrm{a}}$ Tolman cone angle.

9 
1 Table 2 Comparative evaluation of $\mathrm{Ru} \mathrm{NHC} / \mathrm{P}(\mathrm{OR})_{3}$ complexes in $\mathrm{RCM}$

Substrates

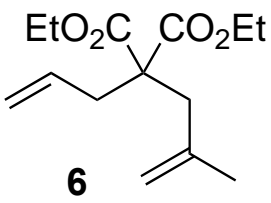

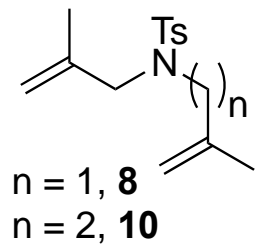
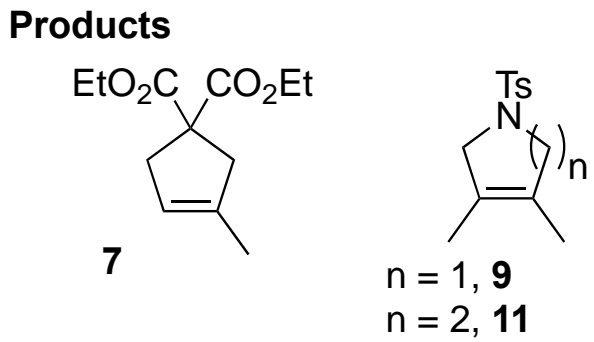

\begin{tabular}{|c|c|c|c|c|c|}
\hline Entry & Substrate & Cat $(\mathrm{mol} \%)$ & Conditions & Conv. $(\%)$ & Lit. \\
\hline 1 & \multirow{11}{*}{6} & Caz-1a $(1 / 0.075)^{\mathrm{a}}$ & \multirow{4}{*}{ toluene, $80^{\circ} \mathrm{C}, 0.5 \mathrm{~h}$} & $>99 />99^{b}$ & 42 \\
\hline 2 & & $\mathbf{C a z}-1 \mathbf{b}(1)^{\mathrm{a}}$ & & 78 & \multirow{3}{*}{43} \\
\hline 3 & & $\operatorname{Caz}-1 \mathrm{c}(1)^{\mathrm{a}}$ & & 35 & \\
\hline 4 & & $\operatorname{Caz}-1 d(1)^{\mathrm{a}}$ & & 98 & \\
\hline 5 & & $\operatorname{Caz}^{-1 a^{+}}(0.1)$ & xylene, $140^{\circ} \mathrm{C}, 15 \mathrm{~min}$ & 99 & 65 \\
\hline 6 & & Caz-2a $(0.025)$ & \multirow[t]{2}{*}{$\mathrm{CH}_{2} \mathrm{Cl}_{2}, 50^{\circ} \mathrm{C}, 2 \mathrm{~h}$} & 96 & \multirow{3}{*}{59} \\
\hline 7 & & Caz-2b $(0.025)$ & & $>99$ & \\
\hline 8 & & Ind-II' $(0.025)$ & $\mathrm{CH}_{2} \mathrm{Cl}_{2}, 30^{\circ} \mathrm{C}, 1 \mathrm{~h}$ & 99 & \\
\hline 9 & & G-II $(0.025)$ & \multirow{3}{*}{ MTBE, $50^{\circ} \mathrm{C}, 8 \mathrm{~h}$} & 91 & \multirow{3}{*}{60} \\
\hline 10 & & Caz-3a $(0.025)$ & & 95 & \\
\hline 11 & & Caz-3b $(0.025)$ & & 93 & \\
\hline 12 & \multirow{9}{*}{8} & Caz-1a $(0.5 / 0.1)^{\mathrm{a}}$ & \multirow{5}{*}{ toluene, $80^{\circ} \mathrm{C}, 5 \mathrm{~h}$} & $>99 / 96^{c}$ & 42 \\
\hline 13 & & Caz-1b $(0.5)^{\mathrm{a}}$ & & 27 & \multirow{4}{*}{43} \\
\hline 14 & & $\operatorname{Caz}-1 \mathrm{c}(0.5)^{\mathrm{a}}$ & & 22 & \\
\hline 15 & & $\operatorname{Caz}-1 d(0.5)^{\mathrm{a}}$ & & 98 & \\
\hline 16 & & Ind-II (0.5) & & 61 & \\
\hline 17 & & $\mathrm{Caz}-1 a^{+}(0.2)$ & xylene, $140^{\circ} \mathrm{C}, 15 \mathrm{~min}$ & 90 & 65 \\
\hline 18 & & G-II (2) & MTBE, $50^{\circ} \mathrm{C}, 8 \mathrm{~h}$ & 25 & 60 \\
\hline 19 & & Caz-3a (2) & & 63 & 00 \\
\hline 20 & & Caz-3b (2) & & 42 & \\
\hline 21 & \multirow{3}{*}{10} & Caz-2a (2) & $\mathrm{CH}_{2} \mathrm{Cl}_{2}, 50^{\circ} \mathrm{C}, 2 \mathrm{~h}$ & 46 & \multirow{3}{*}{59} \\
\hline 22 & & Caz-2b (2) & & 47 & \\
\hline 23 & & Ind-II' (5) & toluene, $80^{\circ} \mathrm{C}, 1 \mathrm{~h}$ & 23 & \\
\hline
\end{tabular}

$3{ }^{\mathrm{a}} \mathrm{Cis}$ isomers were used for compounds caz-1a-d. ${ }^{\mathrm{b}}$ Solvent-free, $120^{\circ} \mathrm{C}$,

4 15h, $0.075 \mathrm{~mol} \% \mathrm{Ru} .{ }^{\mathrm{c}}$ Refluxing toluene, 5h, $0.1 \mathrm{~mol} \% \mathrm{Ru}$. 
1 Table 3 Comparative evaluation of $\mathrm{Ru} \mathrm{NHC} / \mathrm{P}(\mathrm{OR})_{3}$ complexes in enyne

$2 \mathrm{RCM}$

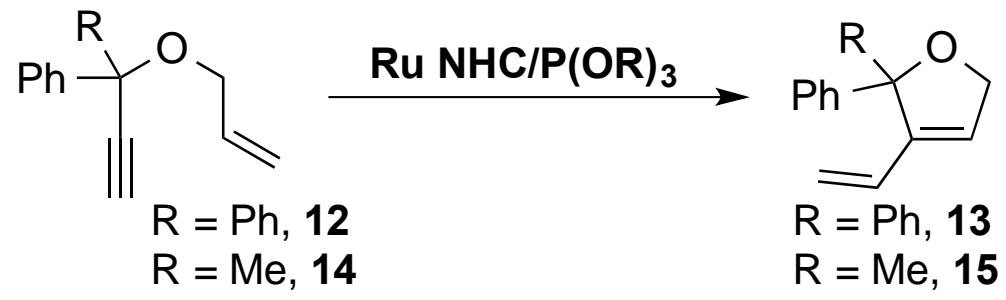

\begin{tabular}{|c|c|c|c|c|c|}
\hline Entry & Substrate & Cat $(\mathrm{mol} \%)^{\mathrm{a}}$ & Conditions & Yield (\%) & Lit. \\
\hline 1 & 12 & Caz-1a $(0.075)$ & toluene, reflux, $15 \mathrm{~h}$ & 68 & 43 \\
\hline 2 & & Caz-1a (1) & toluene, $80^{\circ} \mathrm{C}, 0.5 \mathrm{~h}$ & 75 & 43 \\
\hline 3 & 14 & $\mathrm{Caz}_{-1 \mathbf{a}^{+}}(0.2)$ & xylene, $140^{\circ} \mathrm{C}, 15 \mathrm{~min}$ & 79 & 65 \\
\hline 4 & & Caz-2b $(0.1)$ & $\mathrm{CH}_{2} \mathrm{Cl}_{2}, 50^{\circ} \mathrm{C}, 3 \mathrm{~h}$ & 94 & 59 \\
\hline 5 & & Caz-3a $(0.1)$ & MTBE, $50^{\circ} \mathrm{C}, 8 \mathrm{~h}$ & 78 & 60 \\
\hline
\end{tabular}

$4{ }^{\mathrm{a}}$ Cis isomers were used for compounds caz-1a.

5

6 Table 4 Comparative evaluation of $\mathrm{Ru} \mathrm{NHC} / \mathrm{P}(\mathrm{OR})_{3}$ complexes in $\mathrm{CM}$

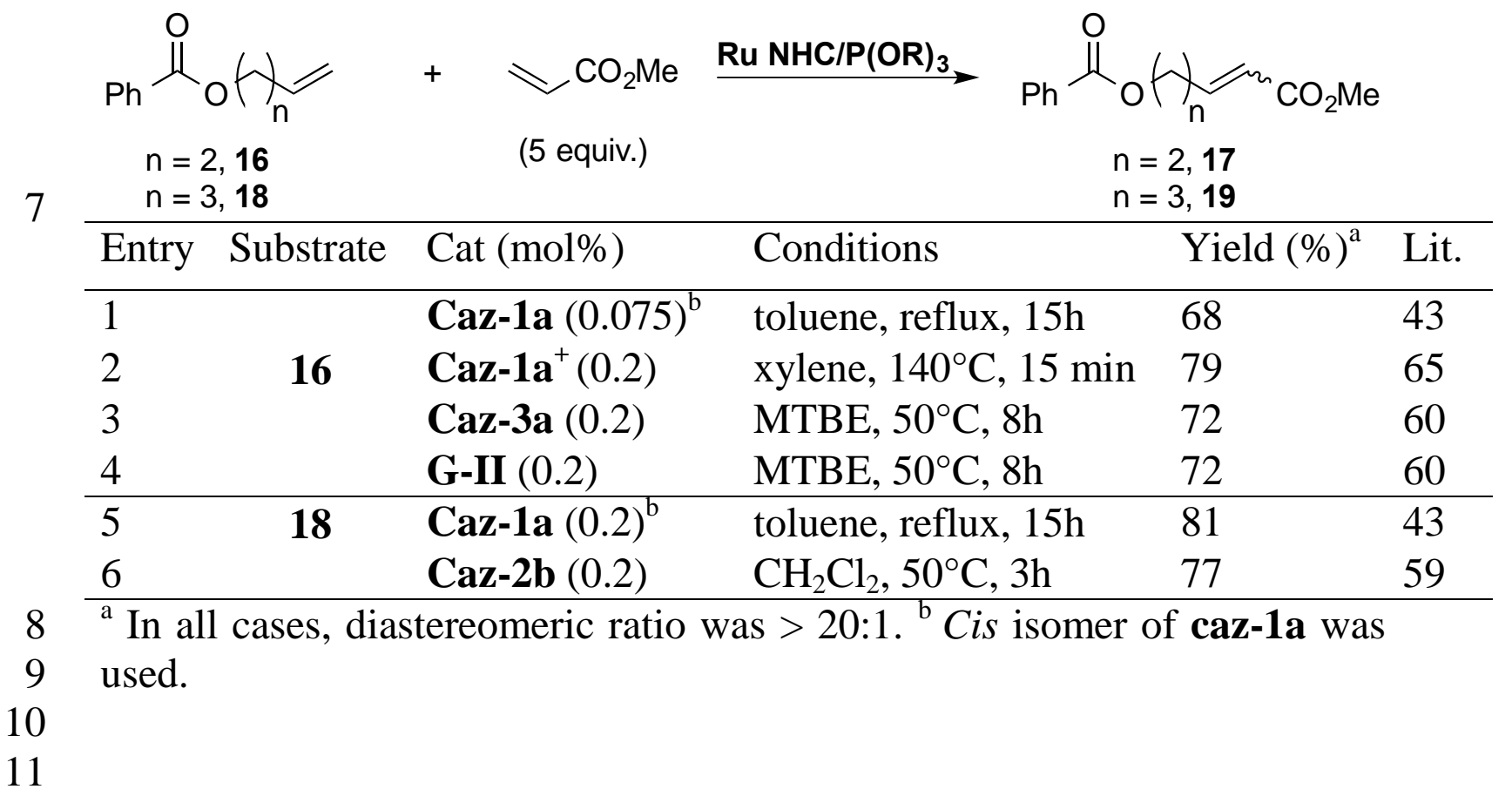


1

2 Table 5 Polymerization with different initiators<smiles>C=CC1CC(C(=C)C)C(C(=O)OC)C1C(=O)OC</smiles>

3

\begin{tabular}{lllll} 
Mon-1 & \multicolumn{4}{c}{ monomer/initiator 300:1 } \\
\hline Entry & Cat & Time (h) & $M_{\mathrm{n}}$ & PDI \\
\hline 1 & cis-Caz-1a & 24 & n.d. & n.d. \\
2 & Caz-2a & 8 & 131000 & 1.6 \\
3 & Ind-II & 4 & 300000 & 2.0 \\
4 & Ind-II' & 2 & 52000 & 1.3 \\
5 & Ind-III & 0.25 & 48000 & 1.05 \\
$6^{\text {a }}$ & cis-Caz-1a & 1 & 106000 & 1.8 \\
\hline
\end{tabular}

$4{ }^{a}$ Toluene, $80^{\circ} \mathrm{C}$.

5 
1 Graphics for use in the Table of Contents

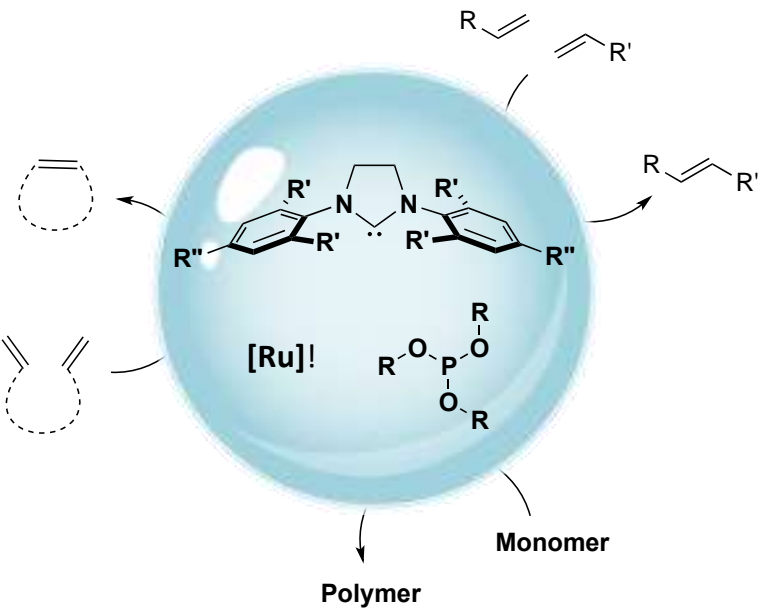

